Correspondence

Elizabeth M. Deane

elizabeth.deane@anu.edu.au

Received 20 June 2009

Revised 12 October 2009

Accepted 13 October 2009

\section{An observational study of the microbiome of the maternal pouch and saliva of the tammar wallaby, Macropus eugenii, and of the gastrointestinal tract of the pouch young}

\author{
Kim-Ly Chhour, ${ }^{1}$ Lyn A. Hinds, ${ }^{2}$ Nicholas A. Jacques ${ }^{3}$ \\ and Elizabeth M. Deane ${ }^{4}$ \\ ${ }^{1}$ Department of Biological Sciences, Division of Environmental and Life Sciences, Macquarie \\ University, NSW 2109, Australia \\ ${ }^{2}$ CSIRO Entomology, GPO Box 1700, Canberra, ACT 2601, Australia \\ ${ }^{3}$ Institute of Dental Research, Westmead Millennium Institute and Westmead Centre for Oral \\ Health, Westmead, NSW 2145, Australia \\ ${ }^{4}$ The Chancelry, The Australian National University, Canberra, ACT 0200, Australia
}

\section{INTRODUCTION}

Metatherian mammals or marsupials are characterized by short gestation periods ranging from only 11 days in the

Abbreviations: ARDRA, amplified rDNA restriction analysis; GIT, gastrointestinal tract.

The GenBank/EMBL/DDBJ accession numbers for the 16S rDNA phylotype sequences determined in this study are GQ358790GQ358918.

Three supplementary tables, showing phylotypes found in the pouch of three tammar wallabies and their closest identity to $16 \mathrm{~S}$ rDNA sequences in GenBank, phylotypes found in the saliva of three adult tammar wallabies and their closest $16 \mathrm{~S}$ rDNA identity to $16 \mathrm{~S}$ rDNA sequences in GenBank, and phylotypes found in the GIT of two pouch young and their closest $16 \mathrm{~S}$ rDNA identity to $16 \mathrm{~S}$ rDNA sequences in GenBank, are available with the online version of this paper. stripe-faced dunnart, Sminthopsis macroura (Renfree, 2006), to 35 days in the koala, Phascolartos cinereus (Tyndale-Biscoe \& Renfree, 1987). At birth, many of the major body systems, including the immune system, are immature, yet the young animal has well-developed forelimbs, mouth and tongue, features which allow it to make its way from the birth canal and into the maternal pouch. Here the young animal attaches itself to a teat and subsequently undergoes the major processes of development and maturation (Fig. 1) (Tyndale-Biscoe \& Janssen, 1988; Tyndale-Biscoe, 2005).

Despite an immature immune system, the pouch young is able to survive in the pouch environment, which is known to contain a range of micro-organisms (Deakin \& Cooper, 2004; Old \& Deane, 1998). It has been presumed that a 


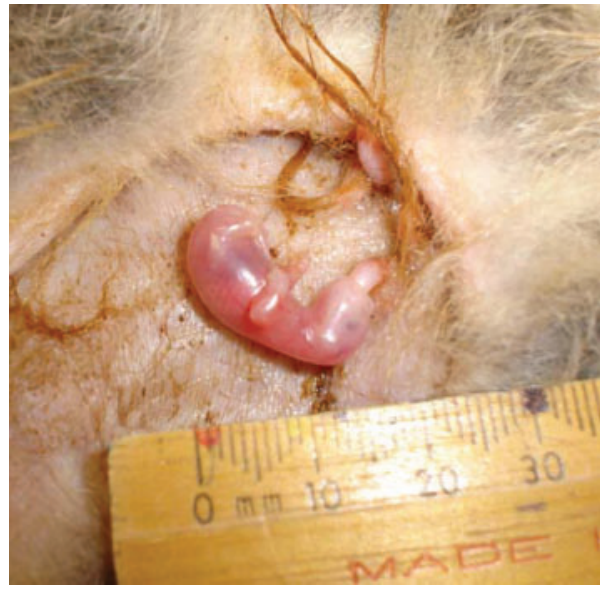

Fig. 1. A day-old pouch young attached to its mother's teat inside the pouch.

range of maternal defence strategies protect the young animal against potentially pathogenic microbial infections. These strategies include immunoglobulins, lysozyme and antimicrobials found in the yolk sac, pouch secretions, milk and saliva (Ambatipudi et al., 2008; Deane et al., 1990; Joss et al., 2009).

To date, the possible contribution of maternally derived micro-organisms to the protection of the young, possibly via competitive exclusion (Cross, 2002; Martin et al., 2007; Savage, 1977), has not been investigated. These microorganisms could arise from a number of maternal sites. Prior to birth of the young marsupial, females groom and lick their pouch, a process which presumably leads to deposition of salivary micro-organisms (Ambatipudi et al., 2008; Tyndale-Biscoe, 2005; Yadav et al., 1972). At birth, the young is exposed to the microbiome of the birth canal and the adjacent urogenital and anal area (Chhour et al., 2008). Subsequently, as the young animal traverses the maternal fur it will also be exposed to a further array of micro-organisms. All of these micro-organisms have the potential to be of benefit or harm to the young animal, and all represent a potential source of the subsequent microbiome of the developing animal.

There have been very few studies of bacterial populations associated with marsupials, and most of these have relied solely on culture-based protocols (Beighton \& Miller, 1977; Deakin \& Cooper, 2004; Lentle et al., 2006; Old \& Deane, 1998; Ouwerkerk et al., 2005; Yadav et al., 1972). It is well recognized that culture-based methods are highly biased, resulting in identification of only a small fraction of the actual microbial diversity (Hugenholtz et al., 1998; Pace, 1997). Recently we used molecular-based methods to compare the bacterial diversity found within the openings of the urogenital and anal tracts of the female tammar wallaby, Macropus eugenii. We found an unexpected degree of bacterial diversity associated with each tract and, despite their close anatomical proximity, each tract was able to maintain its own separate microbiome (Chhour et al., 2008).

In this study we sought to document the microbiome of the maternal pouch and saliva and that of the gastrointestinal tract (GIT) of the pouch young. We used molecular-based methods targeting the $16 \mathrm{~S}$ rDNA gene to investigate the bacteria present in the pouch and saliva from three different tammar wallabies, one carrying a 1-day-old pouch young, another carrying a 4-day-old pouch young and another with no pouch young (nonlactating). To investigate the bacterial diversity of the GIT of the pouch young we collected samples from two different pouch young of the same mothers at three GIT study sites: saliva from the tongue surface, the contents of the stomach cavity and the intestines. This study provides the first comprehensive insight into the bacterial ecology of the GIT of the pouch young and the maternal pouch and saliva, two keys sites of contact between mother and young.

\section{METHODS}

Animals and sample collection. Pouch and saliva swabs from three different female tammar wallabies, tammar 8837, carrying a 1-day-old pouch young, tammar 8817 , carrying a 4 -day-old pouch young, and tammar 1530, with no pouch young, were used in this study. The animals were sourced from two different captive populations maintained in large natural enclosures located at Macquarie University, Sydney, Australia (1530), and CSIRO Sustainable Ecosystems, Canberra, Australia (8837 and 8817). The animal handling and sample collection were approved by Macquarie University's Animal Ethics Committee (reference number 2004/015) or the CSIRO Sustainable Ecosystems Animal Ethics Committee (reference number 04-05-26). Sterile cotton swabs dipped in PBS containing $15 \%(\mathrm{v} / \mathrm{v})$ glycerol were used to collect samples from the pouch and saliva of the three adult female tammar wallabies. The pouch sample was obtained by repeatedly rubbing a cotton swab around the entire surface of the pouch, whilst for collection of oral cavity and salivary bacteria the swab was retained in the animal's mouth for $3 \mathrm{~s}$. The tips of the swabs were broken off into $1.5 \mathrm{ml}$ microfuge tubes containing $300 \mu \mathrm{l}$ PBS and kept on dry ice until sampling was completed, whereupon the samples were stored at $-80{ }^{\circ} \mathrm{C}$ until processed.

Initial attempts to amplify $16 \mathrm{~S}$ rDNA from the bacteria of the GIT samples obtained from pouch young at day 0 (from female 8837) and day 4 (from female 8817 ) at 25 cycles were unsuccessful. Samples were therefore obtained from older pouch young that were the offspring of the same two females (8817 and 8837). These samples were collected from two pouch young, 8817-PY male (40 days old), and 8837-PY female (56 days old), with the ages determined according to head length measurements (Poole et al., 1991). It should be noted that at these ages (40 and 56 days post-partum) the young animals have been attached to the teat from the time of their entry into the pouch. For sampling, the young were removed from the maternal pouch and kept at $37{ }^{\circ} \mathrm{C}$ in a sterile tissue culture incubator $(<2 \mathrm{~h})$ until sacrificed. The tongue and the intestines were removed and placed into sterile $1.5 \mathrm{ml}$ microfuge tubes containing $300 \mu \mathrm{l}$ sterile PBS with $15 \%$ (v/v) glycerol. The stomach and all its contents were placed in a sterile $1.5 \mathrm{ml}$ microfuge tube, and all samples were kept on dry ice until sampling was completed and then stored at $-80{ }^{\circ} \mathrm{C}$ prior to processing. All reagents, swabs and tubes used in the collection protocol were sterilized prior to use. 
DNA extraction. All samples were thawed on ice prior to DNA extraction. Maternal pouch and saliva samples were vortexed for $2 \mathrm{~min}$ to achieve a homogeneous suspension. For pouch young samples the tongue was vortexed vigorously for $2 \mathrm{~min}$ to wash off salivary micro-organisms and to achieve a homogeneous suspension with the storage buffer. The microbial contents of the intestine were obtained by initially disrupting the tissue using a sterile pipette and then subjecting the sample to repeated pipetting. The contents of the intestines were then vortexed vigorously for $2 \mathrm{~min}$ as described above. For the stomach samples a sterile pipette tip was used to pierce the stomach and $2 \mu \mathrm{l}$ of the stomach contents was removed and mixed with $18 \mu \mathrm{l}$ sterile water for DNA extraction. For all samples, with the exception of the stomach, a $20 \mu \mathrm{l}$ aliquot was taken for DNA extraction and mixed with $180 \mu \mathrm{l}$ buffer and incubated at $56{ }^{\circ} \mathrm{C}$ for 2h. This buffer consisted of $10 \mathrm{mM}$ sodium phosphate, $\mathrm{pH} 6.7$, containing $400 \mathrm{mg}$ lysozyme (Roche Applied Science), $200 \mathrm{U}$ mutanolysin (Sigma Aldrich) and $400 \mathrm{mg}$ proteinase K (Qiagen), with $20 \mathrm{mM}$ diethyl pyrocarbonate (Sigma Aldrich). Bacterial cells were lysed with $1 \%(\mathrm{w} / \mathrm{v})$ SDS and $200 \mathrm{mg}$ RNase (Sigma Aldrich) added prior to further incubation at $37^{\circ} \mathrm{C}$ for $10 \mathrm{~min}$ (SmithVaughan et al., 2006). DNA was subsequently isolated and purified using a QIAamp DNA Mini kit (Qiagen), according to the manufacturer's protocol.

Amplified rDNA restriction and sequencing of 16S rDNA genes. Bacterial 16S rDNA genes were amplified by PCR using AmpliTaq Gold with GeneAmp (Applied Biosystems) using the primer pairs F27 (5'-AGAGTTTGATCMTGGCTCAG-3') and R1492 (5'-TACGGYTACCTTGTTACGACTT-3') (Weisburg et al., 1991). These primers have been proven to amplify a wide range of bacterial taxa and to generate PCR amplicons of approximately $1500 \mathrm{bp}$. The conditions for the PCR were as previously described (Chhour et al., 2008). The PCR products were visualized on a $1 \%(\mathrm{w} / \mathrm{v})$ agarose gel, purified using a PCR Clean-Up kit (MO BIO) and cloned into a T-tailed pGEM vector (Promega Life Sciences), before being heat-shocked into Escherichia coli DH5 $\alpha$ (Invitrogen). The transformed E. coli was then cultivated on Luria-Bertani agar plates, and 96 colonies were randomly selected from each of the samples from each of the three adult female wallaby collection sites (i.e. pouch and saliva) to produce two separate clone libraries. From each of the samples of the pouch young GIT (i.e. saliva from the tongue surface, stomach cavity and intestines), 96 colonies were randomly selected to produce a 576 clone library. The cloned inserts within the plasmids were recovered by PCR using vector-specific primers pGEM-F (5'-GGCGGTCGCGGGAATTCGATT- $\left.3^{\prime}\right)$ and pGEM-R (5'-GCCGCGAATTCACTAGTGATT-3') (Aislabie et al., 2006), following lysis of the cells in 96-well plates at $94{ }^{\circ} \mathrm{C}$ for $30 \mathrm{~min}$. The PCR conditions were $94{ }^{\circ} \mathrm{C}$ for $10 \mathrm{~min}$, followed by 25 cycles of $94{ }^{\circ} \mathrm{C}$ for $45 \mathrm{~s}, 55{ }^{\circ} \mathrm{C}$ for $45 \mathrm{~s}$ and $72{ }^{\circ} \mathrm{C}$ for 90 s.

Amplified rDNA restriction analyses (ARDRA; Grimont \& Grimont, 1986) of the PCR products made use of the restriction enzymes RsaI and HaeIII to identify unique restriction patterns within the cloned $16 \mathrm{~S}$ rDNA genes, as ARDRA based on one enzyme is only able to resolve bacterial diversity to the genus level. The restriction profiles were manually compared and all 129 unique restriction profiles from the pouch, saliva and the GIT of the pouch young were sequenced. Partial 16S rDNA gene sequences of approximately $1450 \mathrm{bp}$ in length, representing a specific species or phylotype, were compared with known sequences in GenBank (http://www.ncbi.nlm.nih.gov) using the BLAST search tool (Altschul et al., 1997). Since the majority of the phylotypes were novel species $(<97 \%$ sequence identity to any known 16S rDNA sequences), they were checked to determine whether they were chimaeras by first comparing short sections of each sequence with known sequences in GenBank (Ludwig et al., 1997) and, subsequently, by determining the position of each sequence on a phylogenetic tree with respect to all other phylotypes (see below).
Phylogenetic analysis and diversity index. The cloned $16 \mathrm{~S}$ rDNA sequences from the maternal pouch and saliva samples and the GIT pouch young were aligned using the CLUSTAL w program (Thompson et al., 1994), accessed through BioManager provided by the Australian National Genome Information Service (ANGIS). Neighbour-joining trees (Saitou \& Nei, 1987) were constructed using the Jukes-Cantor parameter in the MEGA version 4 program (Tamura et al., 2007). Bootstrap analyses of 1000 replicates were used to validate the branch points in the trees. The Shannon-Weiner diversity index $\left(\mathrm{H}^{\prime}\right)$ (Gray, 2000) was calculated for each sample.

\section{RESULTS AND DISCUSSION}

\section{Maternal pouch bacteria}

A near full-length $16 \mathrm{~S}$ rDNA library containing 227 clones was generated from the pouch samples collected from three adult female wallabies (8837, 69 clones; 8817, 68 clones; 1530,90 clones). Sequencing of the $16 \mathrm{~S}$ rDNA genes showed that these clones represented 41 different phylotypes belonging to five different bacterial phyla: the Actinobacteria, Firmicutes, Deinococcus-Thermus, Proteobacteria and Bacteroidetes (Fig. 2, Supplementary Table S1). As a species is generally accepted to have $\geqslant 97 \%$ sequence homology and a genus $\geqslant 95 \%$ (Stackebrandt \& Goebel, 1994), 30 of the 41 phylotypes were considered to be novel species and 10 of these could not be grouped into a currently recognized genus.

Bacterial diversity was lowest in the pouch of the female carrying a day-old pouch young, tammar wallaby 8837 with an $\mathrm{H}^{\prime}$ of 1.51 , with eight of the nine different phylotypes detected belonging to the phylum Actinobacteria (Supplementary Table S1). Tammar wallaby 8817 , carrying a 4-day-old pouch young, possessed 19 different phylotypes and an $\mathrm{H}^{\prime}$ of 2.43 , while tammar wallaby 1530, with no pouch young, possessed the greatest diversity, with an $\mathrm{H}^{\prime}$ of 2.46 and 23 phylotypes (Supplementary Table S1). These findings are consistent with those reported using cultivation protocols (Deakin \& Cooper, 2004; Old \& Deane, 1998; Yadav et al., 1972), where a reduction in both diversity and number of bacteria in the pouch of various marsupials occurred at the time of birth. This suggests a need for further investigation into the bacteria found in the pouch at the time of birth of the young, as they may play a role in protection of the pouch young.

Actinobacteria were the most commonly identified bacteria in the maternal pouch, representing $92.5 \%$ of the total number of clones (Table 1) and $82.9 \%$ of the phylotype diversity (Fig. 3). All six of the phylotypes that were represented by $\geqslant 5 \%$ of the isolated clones were from this phylum. Corynebacterium was the most commonly isolated bacterial genus, with five of the six phylotypes belonging to this genus being represented by $\geqslant 5 \%$ of the isolated clones (phylotypes 8837-D0-P-7C, 8837-D0-P-1C, 8817D4-P-1B, 1530-P-2G and 8837-D0-P-1A; Fig. 2, Supplementary Table S1). The genus Corynebacterium comprises more than 60 species and is found in a variety 


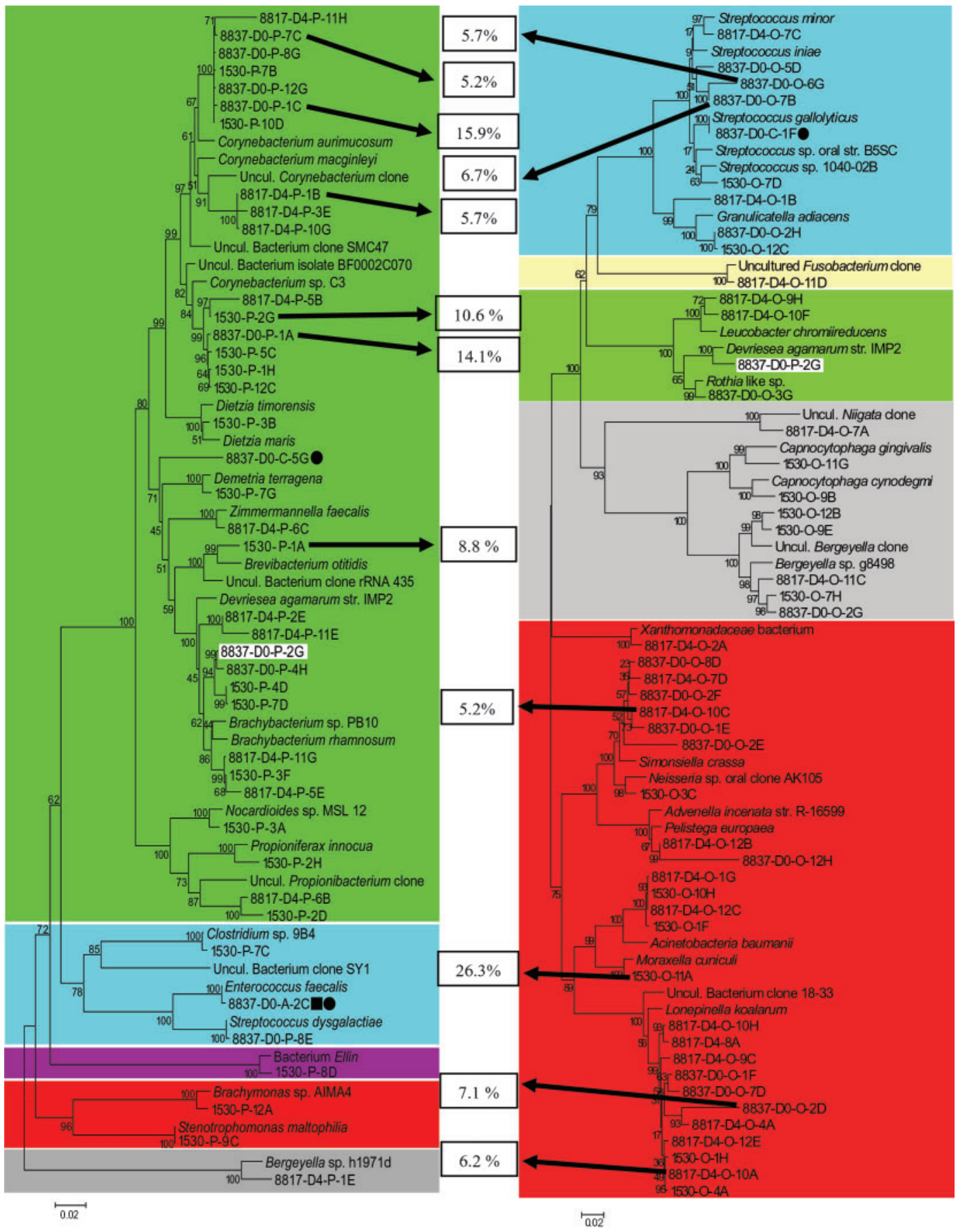

Fig. 2. Phylogenetic trees constructed from near full-length $16 \mathrm{~S}$ rDNA sequences from randomly cloned genes of bacteria isolated from the pouch (left) and saliva (right) of three adult female tammar wallabies. Both trees were constructed by neighbour-joining using the Jukes-Cantor parameter. The trees were bootstrapped 1000 times, and bootstrap values are shown at branch points. Each phylum is defined by a different colour: Actinobacteria, green; Firmicutes, blue; Proteobacteria, red; Bacteroidetes, grey; Fusobacteria, yellow; Deinococcus-Thermus, pink. The phylotype that was found to be common to both the pouch and saliva of the tammar wallaby is highlighted by a white rectangle. The phylotypes which are represented by $\geqslant 5 \%$ of the total clones in the pouch are highlighted by their own box in the centre of the figure giving the percentage of the number of clones. Where a phylotype possessed $\geqslant 97 \%$ identity to a known species, the phylotype was given the species name, otherwise the clone name was used. 
Table 1. Number of clones belonging to different phyla isolated from the pouch and saliva of adult tammar wallabies ND, Not detected.

\begin{tabular}{|c|c|c|c|c|c|c|c|c|}
\hline \multirow[t]{2}{*}{ Phylum } & \multicolumn{4}{|c|}{$\begin{array}{l}\text { Number of clones found in the pouch of three } \\
\text { tammar wallabies }(\%)^{*}\end{array}$} & \multicolumn{4}{|c|}{$\begin{array}{l}\text { Number of clones found in the saliva of three } \\
\text { tammar wallabies }(\%) \dagger\end{array}$} \\
\hline & 1530 & 8837 & 8817 & Total & 1530 & 8837 & 8817 & Total \\
\hline Actinobacteria & 95.6 & 95.7 & 85.3 & 92.5 & ND & 1.4 & 4.4 & 1.9 \\
\hline Proteobacteria & 2.2 & ND & ND & 0.9 & 55.7 & 81.7 & 61.8 & 66.5 \\
\hline Firmicutes & 1.1 & 4.3 & 1.5 & 2.2 & 31.4 & 14.1 & 22.0 & 22.5 \\
\hline Bacteroidetes & ND & ND & 13.2 & 4.0 & 12.9 & 1.4 & 11.8 & 8.6 \\
\hline Fusobacteria & ND & ND & ND & ND & ND & 1.4 & ND & 0.5 \\
\hline Deinococcus-Thermus & 1.1 & ND & ND & 0.4 & ND & ND & $\mathrm{ND}$ & $\mathrm{ND}$ \\
\hline
\end{tabular}

${ }^{*}$ A total of 227 16S rDNA clones were isolated from the pouch of three adult tammar wallabies: tammar wallaby 1530 (no pouch young; 90 clones); tammar wallaby 8837 (carrying a day-old pouch young; 69 clones); tammar wallaby 8817 (carrying a 4-day-old pouch young; 68 clones). $\dagger$ A total of $20916 \mathrm{~S}$ rDNA clones were isolated from the saliva of three adult tammar wallabies: tammar wallaby 1530 (no pouch young; 70 clones); tammar wallaby 8837 (carrying a day-old pouch young; 71 clones); tammar wallaby 8817 (carrying a 4-day-old pouch young; 68 clones).

of environments (Feurer et al., 2004; Funke et al., 1997; Khamis et al., 2005). Several members of this genus are implicated in human disease (Feurer et al., 2004; Van den Velde et al., 2006) and are known to be present in intertriginous areas (Roth \& James, 1988). Our observations of the abundance of Corynebacterium are consistent with culture-based studies of the bacterial flora of the tammar wallaby pouch (Old \& Deane, 1998), but contrast with reported results on the pouch of the brushtail opossum, Trichosurus vulpecula (Deakin \& Cooper, 2004), in which Proteobacteria and not Actinobacteria are the predominant culture isolates.

Phylotype 1530-P-1A, representing $8.8 \%$ of the total number of clones, grouped closest to Brevibacterium otitidis on the phylogenetic tree (Fig. 2). Members of the genus Brevibacterium have been isolated from human toe webs (Roth \& James, 1988), and are regarded as opportunistic pathogens (Pascual et al., 1999; Wauters et al., 2000). This close grouping may indicate that these two organisms share similar properties, particularly the capacity to colonize skin.

The other four phyla, Proteobacteria, Firmicutes, Bacteroidetes and Deinococcus-Thermus, were sparsely represented in samples from the pouches of the three tammar wallabies. In tammar wallaby 8817, the most significant of the four phyla was the Bacteroidetes, which represented $5.3 \%$ of the overall phylotype diversity and $13.2 \%$ of the total number of clones (Fig. 3, Table 1). The phylum Proteobacteria was only detected in tammar wallaby 1530 (with no pouch young), where it contributed $8.7 \%$ of the phylotype diversity and $2.2 \%$ of the total number of clones (Fig. 3, Table 1). The phylum Bacteroidetes was only detected in the pouch of tammar wallaby 8817 , while the phylum Deinococcus-Thermus was only detected in tammar wallaby 1530 (Table 1).

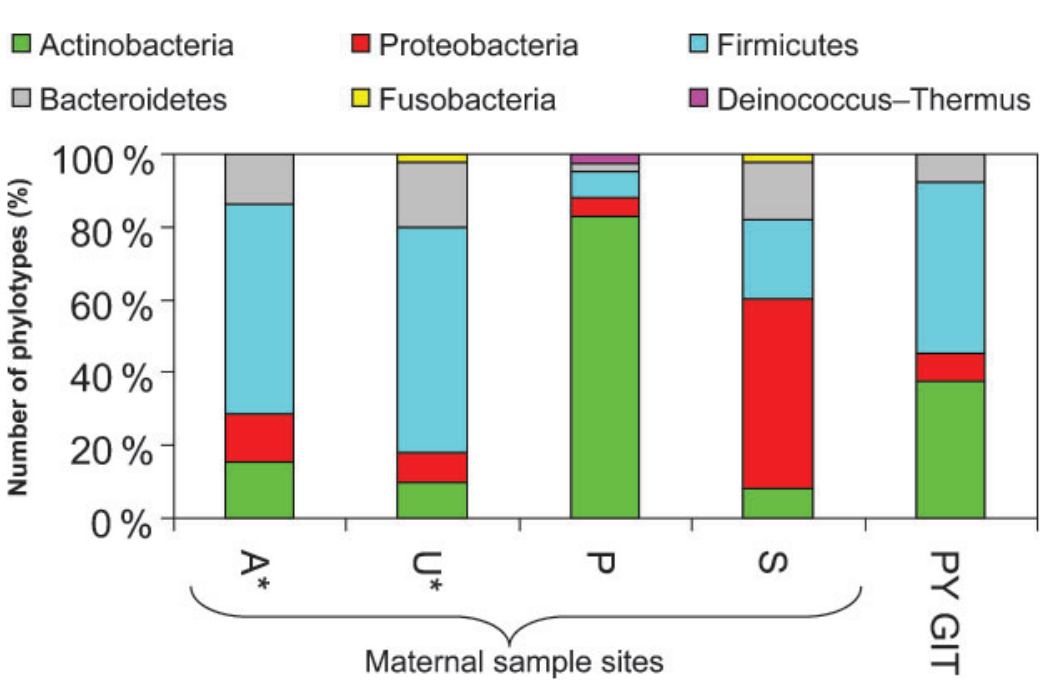

Fig. 3. Histogram showing the diversity of phylotypes based on ARDRA in the different maternal sites compared with the diversity of phylotypes found in the pouch young GIT of the tammar wallaby. A, anal tract; U, urogenital tract; P, pouch; S, saliva; PY GIT, GIT of pouch young. Asterisks indicate that the data were sourced from Chhour et al. (2008). 


\section{Maternal salivary and mouth bacteria}

The final clone library generated from the saliva samples of the three adult female tammar wallabies consisted of 209 clones (71 clones from 8837; 68 clones from 8817; 70 clones from 1530). These salivary clones are considered representative of those to be found in the maternal oral cavity. Tammar wallaby 8837 possessed 17 phylotypes and an $\mathrm{H}^{\prime}$ of 2.31. Tammar wallaby 8817 had an $\mathrm{H}^{\prime}$ of 2.81 and 26 phylotypes, while tammar wallaby 1530 had an $\mathrm{H}^{\prime}$ of 2.59 and 22 phylotypes. In total, 48 different phylotypes were identified that belonged to five different phyla, the Firmicutes, Fusobacteria, Actinobacteria, Bacteroidetes and Proteobacteria (Fig. 2, Supplementary Table S2). Only one phylotype, 8837-D0-P-2G, with $95 \%$ identity to Devrisea agamarum, was found in both the pouch and salivary samples (Fig. 2, Supplementary Tables S1 and S2). This phylotype represented $8.7 \%$ of the total clones isolated from the pouch of tammar wallaby 8837 and $1.5 \%$ of the total salivary clones isolated from tammar wallaby 8817 .

The Proteobacteria were dominant in the saliva of all three wallabies, representing $54.2 \%$ of the phylotype diversity and $66.5 \%$ of the clones isolated (Fig. 3, Table 1). Four of the six phylotypes, 8817-D4-O-10C, 1530-O-11A, 8837-D0-O-2D and $8817-\mathrm{D} 4-\mathrm{O}-10 \mathrm{~A}$, each represented $\geqslant 5 \%$ of the total number of clones isolated (Fig. 2, Supplementary Table S2) and belonged to this phylum. 1530-O-11A was the most frequently detected phylotype and contributed $26.3 \%$ of the total number of clones isolated. This phylotype possessed $98 \%$ identity to Moraxella cuniculi, which has recently been isolated from the GIT of post-weaning piglets ( $\mathrm{Su}$ et al., 2008). However, this species was not detected in the GIT of the pouch young. This may simply reflect the level of sensitivity of the detection system rather than an absence per se. Beighton \& Miller (1977) isolated species of Moraxella from the dental plaque of macropods, which most likely explains why this genus was found only in the saliva of the adult female wallabies. However, the role that this bacterium plays in the oral cavity of the tammar wallaby and other macropods remains unknown.

Phylotype 8837-D0-O-2D was found in the saliva of all three adult tammar wallabies. Due to its low sequence identity $(90 \%)$ to any known $16 \mathrm{~S}$ rDNA, there is little that one can infer about its identity or the role it may play in the oral cavity of the tammar wallaby. On the other hand, phylotype $8817-\mathrm{D} 4-\mathrm{O}-10 \mathrm{~A}$ possessed $95 \%$ identity to Actinobacillus indolicus, which has been isolated from pneumonia lesions and the brains of slaughtered pigs (Blackall et al., 1994; Møller et al., 1993). Phylotype 8817D4-O-10C was found to possess a $96 \%$ sequence identity to Simonsiella crassa. Members of this genus have been isolated from the oral cavity of dogs, cats, sheep and humans, and are considered to be non-pathogenic (Kuhn et al., 1978; Xie \& Yokota, 2005). The role of Simonsiella in any of these mammals, however, remains unknown.

Among salivary bacteria, the Firmicutes represented 18.8\% of the phylotype diversity and $22.5 \%$ of the total number of clones isolated (Fig. 3, Table 1). Two phylotypes each with $>5 \%$ of the total number of isolated clones, phylotypes $8837-\mathrm{D} 0-7 \mathrm{~B}$ and $8837-\mathrm{D} 0-\mathrm{O}-6 \mathrm{G}$, belonged to the Firmicutes. Phylotype 8837-D0-O-6G, which represented $5.7 \%$ of the total number of clones, possessed $98 \%$ identity to Streptococcus iniae and was more frequently identified in tammar wallabies 1530 and 8817 than tammar wallaby 8837 (Supplementary Table S2). S. iniae is reportedly a fish pathogen (Eyngor et al., 2007, 2008; Fuller et al., 2001). Phylotype 8837-D0-O-7B possessed $96 \%$ sequence identity to the $16 \mathrm{~S}$ rDNA of Streptococcus suis, normally considered to be a swine pathogen (Manzin et al., 2008; Wangsomboonsiri et al., 2008), and was more evenly distributed in the saliva of the three animals (Supplementary Table S2). To what extent, if any, these phylotypes can be considered pathogens remains to be determined.

Members identified as belonging to the phylum Bacteroidetes possessed a phylotype diversity of $16.7 \%$, and represented $8.6 \%$ of the total clones isolated from maternal saliva (Fig. 3, Table 1). Members of this phylum were mainly isolated from tammar wallaby 1530 , with only three phylotypes detected in the saliva of the other female wallabies. Actinobacteria were only detected in the tammar wallabies carrying pouch young (8837 and 8817), and Fusobacteria were only detected in tammar wallaby 8837 (Supplementary Table S2).

\section{GIT bacteria of the pouch young}

A 526 clone library was constructed from samples obtained from the GIT of the two pouch young. This included 258 clones from the 40-day-old pouch young, 8817-PY (tongue surface 82 clones, $\mathrm{H}^{\prime} 1.73$; stomach contents 86 clones, $\mathrm{H}^{\prime}$ 2.23; intestine 90 clones, $\mathrm{H}^{\prime} 2.54$ ) and 268 clones from the 56-day-old pouch young, 8837-PY (tongue 92 clones, $\mathrm{H}^{\prime}$ 1.63; stomach 87 clones, $\mathrm{H}^{\prime}$ 1.93; intestines 89 clones, $\mathrm{H}^{\prime}$ 2.84). These clones represented 53 different phylotypes (Supplementary Table S3) belonging to four different phyla, the Firmicutes, Proteobacteria, Actinobacteria and Bacteroidetes (Fig. 4). These findings are in sharp contrast to those reported by Lentle et al. (2006), who found fewer than five different species of bacteria in the GIT of the pouch young. Their relative distribution within the GIT of the pouch young is shown in Table 2 and Fig. 4 . Of the clones isolated, $43.3 \%$ were considered to be novel species as they showed $<97 \%$ identity to any known species (Supplementary Table S3). Although the phylotypes found in this study were not always found throughout the GIT of the pouch young, all the phylotypes with $>5 \%$ of the total number of clones were widely distributed (Fig. 4, Supplementary Table S3).

The GIT of the pouch young was dominated by the Firmicutes, namely the genera Enterococcus and Streptococcus (Fig. 4, Supplementary Table S3). Phylotype $8837-D 0-A-2 C$ represented $20.9 \%$ of the total number of clones isolated and was also found to contribute a 


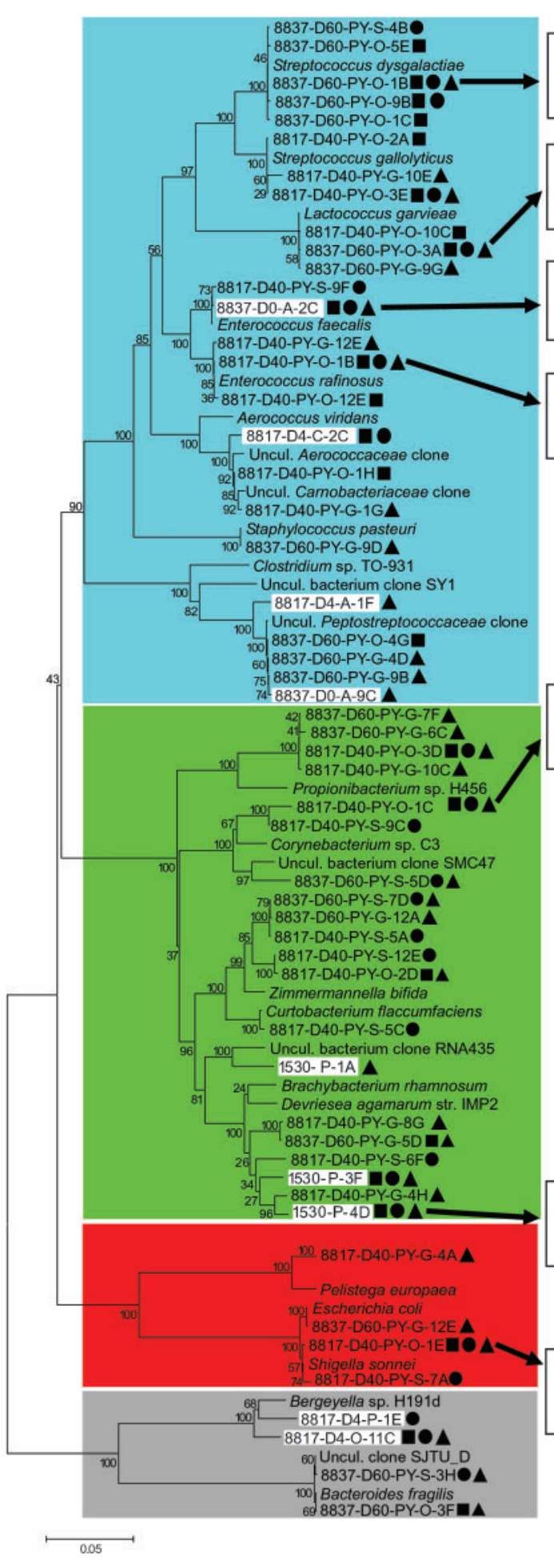

8837-D60-PY-O-1B

$(10.3 \%)$

8837-D60-PY-O-3A

$(5.9 \%)$

8837-D0-A-2C

$(20.9 \%)$

8817-D40-PY-O-1B

$(14.8 \%)$

\section{Firmicutes}

8817-D40-PY-O-1C $(7.4 \%)$

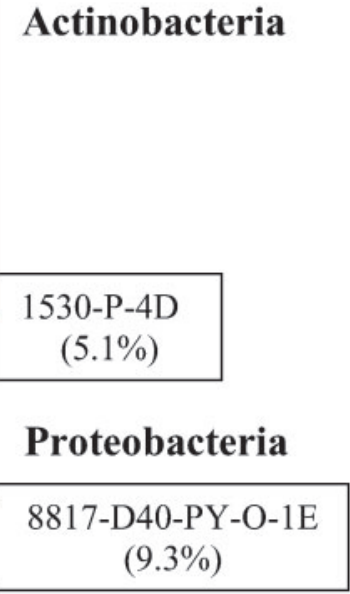

Bacteroidetes
Fig. 4. Phylogenetic tree constructed from near full-length 16S rDNA sequences from randomly cloned genes of bacteria isolated from the tongue surface, stomach cavity and intestines of two tammar wallaby pouch young. The tree was constructed by neighbour-joining using the Jukes-Cantor parameter. The tree was bootstrapped 1000 times, and the bootstrap values are shown at the branch points. Each phylum is defined by a different colour. The phylotypes highlighted by a white rectangle represent the phylotypes that are also found from maternal sources. The shapes next to the phylotypes represent the location within the GIT at which the phylotype was found: $\mathbf{\square}$, tongue surface; $\boldsymbol{O}$, stomach cavity; $\boldsymbol{\Delta}$, intestine. The phylotypes that represent $\geqslant 5 \%$ of the total number of clones are highlighted and expressed as a percentage of the total number of clones found throughout the entire GIT. significant number of clones in all sites (i.e. tongue surface $21.3 \%$, stomach cavity $29.5 \%$ and intestines $12.3 \%$; Supplementary Table S3). This phylotype possessed $99 \%$ identity to Enterococcus faecalis and was also found in the anal and urogenital tracts (Chhour et al., 2008) and the pouch of adult female tammar wallabies. However, in the adult animal, it represented $<1 \%$ of the total clones isolated. These observations suggest that differences in the mucosal environment of the GIT, and the availability of nutrients from maternal milk to the developing pouch young, enable this species to proliferate in the GIT. Pertinent to the concept that these bacteria play a protective role in marsupials is the fact that strains of Enterococcus faecalis are known to reduce the colonization 
Table 2. Combined number of clones belonging to different phyla isolated from the GIT of two pouch young

\begin{tabular}{|lcccr|}
\hline Phylum & \multicolumn{4}{c}{$\begin{array}{c}\text { Number of clones isolated from the } \\
\text { GIT of two pouch young }(\%)^{*}\end{array}$} \\
\cline { 2 - 5 } & $\begin{array}{l}\text { Tongue } \\
\text { surface }\end{array}$ & $\begin{array}{c}\text { Stomach } \\
\text { cavity }\end{array}$ & Intestines & Total \\
& 9.2 & 20.8 & 42.5 & 24.3 \\
\hline Actinobacteria & 7.5 & 17.9 & 7.3 & 10.8 \\
Proteobacteria & 82.2 & 58.4 & 44.7 & 61.6 \\
Firmicutes & 1.1 & 2.9 & 5.6 & 3.2 \\
Bacteroidetes & & & & \\
\hline
\end{tabular}

${ }^{*}$ A combined total of $52616 \mathrm{~S}$ rDNA clones were isolated from three different segments of the GIT of two tammar wallaby pouch young aged 40 and 56 days. Tongue surface, 174 clones; stomach content, 173 clones; intestines, 179 clones.

of pathogens. For instance, strains of Enterococcus faecalis inhibit Staphylococcus aureus colonization of mucosal surfaces by production of bacteriocins or by lowering the $\mathrm{pH}$ (Alomar et al., 2008a, b). Although strains of Enterococcus faecalis are also known to be opportunistic pathogens (Punj \& John, 2008), the role that the strains of Enterococcus faecalis found in this study may play in the GIT of the pouch young is not known.

Phylotype 8817-D40-PY-O-1B possessed $99 \%$ identity to Enterococcus raffinosus. This phylotype made up $14.8 \%$ of the total clones isolated (Fig. 4, Supplementary Table S3). As with Enterococcus faecalis, Enterococcus raffinosus was found throughout the GIT of the pouch young. However, it was not isolated from the pouch, saliva or the cloaca (Chhour et al., 2008) of the adult tammar wallabies. Phylotype 8837-D60-PY-O-3A showed a $99 \%$ match to Lactococcus garvieae. This phylotype contributed $5.9 \%$ of the total number of clones found in the GIT (Fig. 4, Supplementary Table S3).

Within the genus Streptococcus, phylotype 8837-D60-PYO-1B showed a $99 \%$ match to the $16 \mathrm{~S}$ rDNA of Streptococcus dysgalactiae and represented $10.3 \%$ of the total number of clones isolated. The bulk of these clones were from the surface of the tongue $(29.3 \%)$, with only two clones being isolated from the stomach and one from the intestines (Supplementary Table S3). Strains of $S$. dysgalactiae are associated with a variety of diseases (Denamiel et al., 2005; Kawata et al., 2003; Vela et al., 2006), and strains of $S$. dysgalactiae have previously been reported in the cloaca of the adult female tammar wallaby (Chhour et al., 2008). This species was also detected in the pouch of tammar wallaby 8837 carrying a day-old pouch young. However, none of the maternal phylotypes was found in the GIT of the pouch young.

The phylum Actinobacteria contributed $37.7 \%$ of the phylotype diversity and $24.3 \%$ of the total number of clones in the GIT of the pouch young (Fig. 3, Table 2).
Phylotype $8817-\mathrm{D} 40-\mathrm{PY}-\mathrm{O}-1 \mathrm{C}$ represented $7.4 \%$ of the total number of clones and possessed $94 \%$ identity to Corynebacterium sp. C3 (Supplementary Table S3). Phylotype 1530-P-4D represented $5.1 \%$ of the isolated clones and was found throughout the GIT of both the pouch young. It possessed $96 \%$ identity to Devrisea agamarum str. IMP2 (GenBank accession no. EU009865; Fig. 4, Supplementary Table S3). This phylotype was also found in the pouch of tammar wallaby 1530, but not in the two tammar wallabies carrying pouch young (Supplementary Table S1).

In contrast to the Firmicutes and the Actinobacteria, the phyla Proteobacteria and Bacteroidetes were poorly represented within the GIT of the pouch young (Fig. 4, Supplementary Table S3). The most numerous phylotype was $8817-\mathrm{D} 40-\mathrm{PY}-\mathrm{O}-1 \mathrm{E}$, which possessed $99 \%$ identity to E. coli and represented $9.3 \%$ of the total number of clones (Fig. 4, Supplementary Table S3). Indigenous E. coli strains are known to prevent colonization and infection by enterotoxigenic strains of $E$. coli in several mouse and pig models (McFarland, 2000). The high presence of phylotype 8817-D40-PY-O-1E throughout the GIT of both pouch young bears further investigation, as this phylotype may serve its host in a similar manner.

The bacterial composition of the GIT of the two pouch young was remarkably similar in that each of the seven phylotypes that represented $>5 \%$ of the total number of clones isolated was found throughout the GIT. This may be due to the immaturity of the GIT of the pouch young at the age of sampling (Dra, 1986), yet it contrasts to what was observed in maternal samples. Here, the bacterial composition was found to be unique at all the sites sampled, which is consistent with recent observations in humans and other eutherian mammals (Fierer et al., 2008; Ley et al., $2006,2008)$. One other interesting possibility that we have been unable to explore, given the very small (microlitre) volumes available, is that the bacterial flora of the GIT of the young arises from the maternal milk. Recently, Martin et al. (2007) reported that bacteria commonly isolated from human infant faeces, such as staphylococci, streptococci, micrococci, lactobacilli and enterococci, are also isolated from breast milk and are considered as part of the normal flora. This range of bacteria is similar to what we found in the GIT of the pouch young, where the enterococci were the most commonly isolated, followed by the streptococci. Interestingly, no lactobacilli have been detected at any site in either the adult animals or the pouch young (Supplementary Table S3; Chhour et al., 2008).

\section{Phylotypes found both in the pouch young GIT and in maternal samples}

Only nine phylotypes out of the 53 detected in the GIT of the pouch young matched those found in the pouch and saliva of the three adult female tammar wallabies and those found in the urogenital and anal openings of tammar wallabies 8837 and 8817 (Chhour et al., 2008) (Table 3). 
Table 3. Phylotypes common to both maternal sites and the GIT of pouch young

ND, Not detected.

\begin{tabular}{|c|c|c|c|c|c|c|c|}
\hline \multirow[t]{2}{*}{ Phylotype } & \multicolumn{4}{|c|}{ Distribution of the phylotypes at maternal sites (\%) } & \multicolumn{3}{|c|}{$\begin{array}{l}\text { Distribution of the phylotypes in } \\
\text { the GIT of pouch young }(\%)\end{array}$} \\
\hline & $\begin{array}{l}\text { Urogenital } \\
\text { opening* }\end{array}$ & Anal opening ${ }^{\star}$ & Pouch & Saliva & $\begin{array}{l}\text { Tongue } \\
\text { surface }\end{array}$ & $\begin{array}{l}\text { Stomach } \\
\text { cavity }\end{array}$ & Intestine \\
\hline $8817-\mathrm{D} 4-\mathrm{C}-2 \mathrm{C}$ & 1.2 & $0.7 \dagger$ & $\mathrm{ND}$ & $\mathrm{ND}$ & $0.6 \ddagger$ & $0.6 \neq$ & $\mathrm{ND}$ \\
\hline 8817-D4-A-1F & $0.6 \$$ & $8.1 \S$ & ND & ND & ND & $\mathrm{ND}$ & $0.6 \ddagger 11$ \\
\hline 8837-D0-A-2C & $0.6 \dagger$ & $1.4 \dagger$ & $1.5 \$$ & ND & $21.3 \ddagger 11$ & $29.5 \ddagger 11$ & $12.3 \ddagger 11$ \\
\hline 8837-D0-A-9C & $\mathrm{ND}$ & 1.4 & ND & $\mathrm{ND}$ & $\mathrm{ND}$ & $\mathrm{ND}$ & 0.611 \\
\hline 1530-P-1A & $\mathrm{ND}$ & $\mathrm{ND}$ & 22.29 & ND & $\mathrm{ND}$ & $\mathrm{ND}$ & 0.611 \\
\hline $1530-\mathrm{P}-3 \mathrm{~F}$ & $\mathrm{ND}$ & ND & 4.4 & ND & 0.611 & 0.611 & 2.211 \\
\hline $1530-P-4 D$ & $\mathrm{ND}$ & ND & 11.19 & ND & $1.7 \ddagger 11$ & $4.6 \neq 11$ & $8.9 \ddagger 11$ \\
\hline 8817-D4-P-1E & $\mathrm{ND}$ & ND & $13.2 \S$ & $\mathrm{ND}$ & ND & 1.211 & $\mathrm{ND}$ \\
\hline 8817-D4-O-11C & $\mathrm{ND}$ & ND & ND & $8.8 \$ 2.99$ & $0.6 \ddagger 11$ & $0.6 \neq 11$ & $3.4 \$ 11$ \\
\hline
\end{tabular}

${ }^{\star}$ Data from Chhour et al. (2008).

$\dagger$ Phylotype found in adult female tammar wallaby 8837 .

$\$$ Phylotype found in pouch young of tammar wallaby 8817 .

\$Phylotype found in adult female tammar wallaby 8817.

IIPhylotype found in pouch young of tammar wallaby 8837 .

SPylotype found in adult female tammar wallaby 1530.

Interestingly, these nine phylotypes were not necessarily detected in the mother of a given pouch young. For example, phylotype 1530-P-4D was isolated only from the tammar wallaby with no pouch young, yet was found in the GIT of both the pouch young. It may well be that the bacteria are present but in numbers that are below the detection capabilities of the methods used in this study, as the probability of detecting a cloned $16 \mathrm{~S}$ rDNA with $95 \%$ confidence using a sample size of 96 requires a species to be present at a level of $\geqslant 3 \%$ of the population (Chhour et al., 2005).

Phylotype 8837-D0-A-2C, which was isolated throughout the GIT of the pouch young, was found only sparsely in the maternal pouch and urogenital and anal openings, and was not detected in the saliva. In contrast, phylotype 1530-P-1A was found to contribute $22.2 \%$ of the total number of clones isolated from the pouch of tammar wallaby 1530 , yet represented only $0.6 \%$ of the clones from the intestines of the pouch young (Table 3 ). Maternal phylotypes 1530-P-3F and $1530-\mathrm{P}-4 \mathrm{D}$ were found throughout the GIT of the pouch young, while phylotype $8817-\mathrm{D} 4-\mathrm{P}-1 \mathrm{E}$ was only found in the stomach cavity.

The only phylotype that was found in both the GIT of the pouch young and the maternal saliva was phylotype 8817D4-O-11C, which possessed a $96 \% 16 \mathrm{~S}$ rDNA sequence identity to Bergeyella species clone g8498. This phylotype was found in adult tammar wallabies 8817 and 1530, but not in tammar wallaby 8837 , the female carrying the 1-dayold pouch young. This phylotype was found throughout the GIT of the pouch young (Table 3, Fig. 4).

\section{CONCLUSION}

This study has documented the microbiome of the adult pouch and saliva of the tammar wallaby and that of the GIT of the pouch young, and has laid the foundation for further studies investigating the source of a young animal's microbiome. This study has highlighted the fact that the bacterial microbiome of the tammar wallaby is much more diverse than was previously thought based solely on cultivable bacteria, especially as far as the GIT of the pouch young is concerned. In addition, we observed that the maternal and pouch young microbiomes were able to maintain their uniqueness, despite their close proximity to one another.

\section{ACKNOWLEDGEMENTS}

K.-L. C. was the recipient of a Macquarie University Research Awards for Areas and Centres of Excellence (RAACE) Postgraduate Scholarship.

\section{REFERENCES}

Aislabie, J. M., Chhour, K.-L., Saul, D. J., Miyauchi, S., Ayton, J., Paetzold, R. F. \& Balks, M. R. (2006). Dominant bacteria in soils of Marble Point and Wright Valley, Victoria Land, Antarctica. Soil Biol Biochem 38, 3041-3056.

Alomar, J., Lebert, A. \& Montel, M. C. (2008a). Effect of temperature and $\mathrm{pH}$ on growth of Staphylococcus aureus in co-culture with Lactococcus garvieae. Curr Microbiol 56, 408-412.

Alomar, J., Loubiere, P., Delbes, C., Nouaille, S. \& Montel, M. C. (2008b). Effect of Lactococcus garvieae, Lactococcus lactis and 
Enterococcus faecalis on the behaviour of Staphylococcus aureus in microfiltered milk. Food Microbiol 25, 502-508.

Altschul, S. F., Madden, T. L., Schaffer, A. A., Zhang, J., Zhang, Z., Miller, W. \& Lipman, D. J. (1997). Gapped BLAST and PSI-BLAST: a new generation of protein database search programs. Nucleic Acids Res 25, 3389-3402.

Ambatipudi, K., Joss, J., Raftery, M. \& Deane, E. M. (2008). A proteomic approach to analysis of antimicrobial activity in marsupial pouch secretions. Dev Comp Immunol 32, 108-120.

Beighton, D. \& Miller, W. A. (1977). A microbiological study of normal flora of macropod dental plaque. J Dent Res 56, 995-1000.

Blackall, P. J., McKechnie, K. \& Sharp, T. (1994). Isolation of Haemophilus taxon D from pigs in Australia. Aust Vet J 71, 263.

Chhour, K.-L., Nadkarni, M. A., Byun, R., Martin, F. E., Jacques, N. A. \& Hunter, N. (2005). Molecular analysis of microbial diversity in advanced caries. J Clin Microbiol 43, 843-849.

Chhour, K.-L., Hinds, L. A., Deane, E. M. \& Jacques, N. A. (2008). The microbiome of the cloacal openings of the urogenital and anal tracts of the tammar wallaby, Macropus eugenii. Microbiology 154, 15351543.

Cross, M. L. (2002). Microbes versus microbes: immune signals generated by probiotic lactobacilli and their role in protection against microbial pathogens. FEMS Immunol Med Microbiol 34, 245-253.

Deakin, J. E. \& Cooper, D. W. (2004). Characterisation of and immunity to the aerobic bacteria found in the pouch of the brushtail possum Trichosurus vulpecula. Comp Immunol Microbiol Infect Dis 27, 33-46.

Deane, E. M., Cooper, D. W. \& Renfree, M. B. (1990). Immunoglobulin $\mathrm{G}$ levels in fetal and newborn Tammar Wallabies (Macropus eugenii). Reprod Fertil Dev 2, 369-375.

Denamiel, G., Llorente, P., Carabella, M., Rebuelto, M. \& Gentilini, E. (2005). Anti-microbial susceptibility of Streptococcus spp. isolated from bovine mastitis in Argentina. J Vet Med B Infect Dis Vet Public Health 52, 125-128.

Dra, S. (1986). Early development of the digestive tract of Macropus eugenii (the tammar wallaby). MSc thesis, Macquarie University.

Eyngor, M., Chilmonczyk, S., Zlotkin, A., Manuali, E., Lahav, D., Ghittino, C., Shapira, R., Hurvitz, A. \& Eldar, A. (2007). Transcytosis of Streptococcus iniae through skin epithelial barriers: an in vitro study. FEMS Microbiol Lett 277, 238-248.

Eyngor, M., Tekoah, Y., Shapira, R., Hurvitz, A., Zlotkin, A., Lublin, A. \& Eldar, A. (2008). Emergence of novel Streptococcus iniae exopolysaccharide-producing strains following vaccination with nonproducing strains. Appl Environ Microbiol 74, 6892-6897.

Feurer, C., Clermont, D., Bimet, F., Candrea, A., Jackson, M., Glaser, P., Bizet, C. \& Dauga, C. (2004). Taxonomic characterization of nine strains isolated from clinical and environmental specimens, and proposal of Corynebacterium tuberculostearicum sp. nov. Int J Syst Evol Microbiol 54, 1055-1061.

Fierer, N., Hamady, M., Lauber, C. L. \& Knight, R. (2008). The influence of sex, handedness, and washing on the diversity of hand surface bacteria. Proc Natl Acad Sci U S A 105, 17994-17999.

Fuller, J. D., Bast, D. J., Nizet, V., Low, D. E. \& de Azavedo, J. C. S. (2001). Streptococcus iniae virulence is associated with a distinct genetic profile. Infect Immun 69, 1994-2000.

Funke, G., von Graevenitz, A., Clarridge, J. E., III \& Bernard, K. A. (1997). Clinical microbiology of coryneform bacteria. Clin Microbiol Rev 10, 125-159.

Gray, J. S. (2000). The measurement of marine species diversity, with an application to the benthic fauna of the Norwegian continental shelf. J Exp Mar Biol Ecol 250, 23-49.
Grimont, F. \& Grimont, P. A. D. (1986). Ribosomal ribonucleic acid gene restriction patterns as potential taxonomic tools. Ann Inst Pasteur Microbiol 137B, 165-175.

Hugenholtz, P., Goebel, B. M. \& Pace, N. R. (1998). Impact of culture-independent studies on the emerging phylogenetic view of bacterial diversity. J Bacteriol 180, 4765-4774.

Joss, J. L., Molloy, M. P., Hinds, L. A. \& Deane, E. M. (2009). A longitudinal study of the protein components of marsupial milk from birth to weaning in the tammar wallaby (Macropus eugenii). Dev Comp Immunol 33, 152-161.

Kawata, K., Minakami, T., Mori, Y., Katsumi, M., Kataoka, Y., Ezawa, A., Kikuchi, N. \& Takahashi, T. (2003). rDNA sequence analyses of Streptococcus dysgalactiae subsp. equisimilis isolates from pigs. Int J Syst Evol Microbiol 53, 1941-1946.

Khamis, A., Raoult, D. \& La Scola, B. (2005). Comparison between $r p o B$ and 16S rRNA gene sequencing for molecular identification of 168 clinical isolates of Corynebacterium. J Clin Microbiol 43, 19341936.

Kuhn, D. A., Gregory, D. A., Buchanan, G. E. J., Nyby, M. D. \& Daly, K. R. (1978). Isolation, characterization, and numerical taxonomy of Simonsiella strains from the oral cavities of cats, dogs, sheep, and humans. Arch Microbiol 118, 235-241.

Lentle, R. G., Dey, D., Hulls, C., Mellor, D. J., Moughan, P. J., Stafford, K. J. \& Nicholas, K. (2006). A quantitative study of the morphological development and bacterial colonisation of the gut of the tammar wallaby Macropus eugenii and in-pouch development. J Comp Physiol [B] 176, 763-774.

Ley, R. E., Peterson, D. A. \& Gordon, J. I. (2006). Ecological and evolutionary forces shaping microbial diversity in the human intestine. Cell 124, 837-848.

Ley, R. E., Hamady, M., Lozupone, C., Turnbaugh, P. J., Ramey, R. R., Bircher, J. S., Schlegel, M. L., Tucker, T. A., Schrenzel, M. D. \& other authors (2008). Evolution of mammals and their gut microbes. Science 320, 1647-1651.

Ludwig, W., Bauer, S. H., Bauer, M., Held, I., Kirchhof, G., Schulze, R., Huber, I., Spring, S., Hartmann, A. \& Schleifer, K. H. (1997). Detection and in situ identification of representatives of a widely distributed new bacterial phylum. FEMS Microbiol Lett 153, 181-190.

Manzin, A., Palmieri, C., Serra, C., Saddi, B., Princivalli, M. S., Loi, G., Angioni, G., Tiddia, F., Varaldo, P. E. \& Facinelli, B. (2008). Streptococcus suis meningitis without history of animal contact, Italy. Emerg Infect Dis 14, 1946-1948.

Martin, R., Heilig, G. H. J., Zoetendal, E. G., Smidt, H. \& Rodriguez, J. M. (2007). Diversity of the Lactobacillus group in breast milk and vagina of healthy women and potential role in the colonization of the infant gut. J Appl Microbiol 103, 2638-2644.

McFarland, L. V. (2000). Normal flora: diversity and functions. Microb Ecol Health Dis 12, 193-207.

Møller, K., Andersen, L. V., Christensen, G. \& Kilian, M. (1993). Optimalization of the detection of NAD dependent Pasteurellaceae from the respiratory tract of slaughterhouse pigs. Vet Microbiol 36, 261-271.

Old, J. M. \& Deane, E. M. (1998). The effect of oestrus and the presence of pouch young on aerobic bacteria isolated from the pouch of the tammar wallaby, Macropus eugenii. Comp Immunol Microbiol Infect Dis 21, 237-245.

Ouwerkerk, D., Klieve, A. V., Forster, R. J., Templeton, J. M. \& Maguire, A. J. (2005). Characterization of culturable anaerobic bacteria from the forestomach of an eastern grey kangaroo, Macropus giganteus. Lett Appl Microbiol 41, 327-333.

Pace, N. R. (1997). A molecular view of microbial diversity and the biosphere. Science 276, 734-740. 
Pascual, M., Hugas, M., Badiola, J. I., Monfort, J. M. \& Garriga, M. (1999). Lactobacillus salivarius CTC2197 prevents Salmonella enteritidis colonization in chickens. Appl Environ Microbiol 65, 4981-4986.

Poole, W. E., Simms, N. G., Wood, J. T. \& Lubulwa, M. (1991). Tables for Age Determination of the Kangaroo Island Wallaby (Tammar), Macropus eugenii, from Body Measurements. Canberra: CSIRO.

Punj, S. \& John, G. H. (2008). Physiological characterization of Enterococcus faecalis during azoreductase activity. Microb Ecol Health Dis 20, 65-73.

Renfree, M. B. (2006). Society for Reproduction Biology Founders' Lecture 2006 - life in the pouch: womb with a view. Reprod Fertil Dev 18, 721-734.

Roth, R. R. \& James, W. D. (1988). Microbial ecology of the skin. Annu Rev Microbiol 42, 441-464.

Saitou, N. \& Nei, M. (1987). The neighbor-joining method: a new method for reconstructing phylogenetic trees. Mol Biol Evol 4, 406-425.

Savage, D. C. (1977). Microbial ecology of the gastrointestinal tract. Annu Rev Microbiol 31, 107-133.

Smith-Vaughan, H., Byun, R., Nadkarni, M. A., Jacques, N. A., Hunter, N., Halpin, S., Morris, P. \& Leach, A. (2006). Measuring nasal bacterial load and its association with otitis media. BMC Ear Nose Throat Disord 6, 10.

Stackebrandt, E. \& Goebel, B. M. (1994). Taxonomic note: a place for DNA-DNA reassociation and $16 \mathrm{~S}$ rRNA sequence analysis in the present species definition in bacteriology. Int J Syst Bacteriol 44, 846-849.

Su, Y., Yao, W., Perez-Gutierrez, O. N., Smidt, H. \& Zhu, W.-Y. (2008). Changes in abundance of Lactobacillus spp. and Streptococcus suis in the stomach, jejunum and ileum of piglets after weaning. FEMS Microbiol Ecol 66, 546-555.

Tamura, K., Dudley, J., Nei, M. \& Kumar, S. (2007). MEGA4: Molecular Evolutionary Genetics Analysis (MEGA) software version 4.0. Mol Biol Evol 24, 1596-1599.

Thompson, J. D., Higgins, D. G. \& Gibson, T. J. (1994). Clustal W: improving the sensitivity of progressive multiple sequence alignment through sequence weighting, position-specific gap penalties and weight matrix choice. Nucleic Acids Res 22, 4673-4680.
Tyndale-Biscoe, H. (2005). Life of Marsupials, 2nd edn. Collingwood, Victoria: CSIRO Publishing.

Tyndale-Biscoe, C. H. \& Janssen, P. A. (1988). Introduction. In The Developing Marsupial - Models for Biomedical Research, pp. 1-7. Edited by C. H. Tyndale-Biscoe \& P. A. Janssen. Berlin, Heidelberg: Springer.

Tyndale-Biscoe, C. H. \& Renfree, M. (1987). Reproductive Physiology of Marsupials. London: Cambridge University Press.

Van den Velde, S., Lagrou, K., Desmet, K., Wauters, G. \& Verhaegen, J. (2006). Species identification of corynebacteria by cellular fatty acid analysis. Diagn Microbiol Infect Dis 54, 99-104.

Vela, A. I., Falsen, E., Simarro, I., Rollan, E., Collins, M. D., Dominguez, L. \& Fernandez-Garayzabal, J. F. (2006). Neonatal mortality in puppies due to bacteremia by Streptococcus dysgalactiae subsp. dysgalactiae. J Clin Microbiol 44, 666-668.

Wangsomboonsiri, W., Luksananun, T., Saksornchai, S., Ketwong, K. \& Sungkanuparph, S. (2008). Streptococcus suis infection and risk factors for mortality. J Infect 57, 392-396.

Wauters, G., Van Bosterhaut, B., Avesani, V., Cuvelier, R., Charlier, J., Janssens, M. \& Delmee, M. (2000). Peritonitis due to Brevibacterium otitidis in a patient undergoing continuous ambulatory peritoneal dialysis. J Clin Microbiol 38, 4292-4293.

Weisburg, W. G., Barns, S. M., Pelletier, D. A. \& Lane, D. J. (1991). $16 \mathrm{~S}$ ribosomal DNA amplification for phylogenetic study. J Bacteriol 173, 697-703.

Xie, C.-H. \& Yokota, A. (2005). Phylogenetic analysis of Alysiella and related genera of Neisseriaceae: proposal of Alysiella crassa comb. nov., Conchiformibium steedae gen. nov., comb. nov., Conchiformibium kuhniae sp. nov. and Bergeriella denitrificans gen. nov., comb. nov. J Gen Appl Microbiol 51, 1-10.

Yadav, M., Stanley, N. F. \& Waring, H. (1972). The microflora of the gut of the pouch-young and the pouch of a marsupial, Setonix brachyurus. J Gen Microbiol 70, 437-442.

Edited by: H. J. Flint 